\title{
ULCERAÇÕES GENITAIS HERPÉTICAS RECALCITRANTES TRATADAS COM IMIQUIMOD ASSOCIADO AO VALACICLOVIR
}

\author{
Diogo Matos', João Alves', Ana Marta António', Ricardo Coelho², Elvira Bártolo³ \\ 'Interna(o) do Internato Complementar de Dermatologia e Venereologia/Resident, Dermatology and Venereology \\ ${ }^{2}$ Assistente Hospitalar de Dermatologia e Venereologia/Consultant, Dermatology and Venereology, \\ ${ }^{3}$ Chefe de Serviço de Dermatologia e Venereologia, Directora do Serviço de Dermatologia e Venereologia/ Chief and \\ Head of Dermatology and Venereology Department \\ Hospital Garcia de Orta, Almada, Portugal
}

RESUMO - O vírus herpes simplex é o principal responsável por ulcerações genitais de etiologia infecciosa. No contexto de imunodeficiência, manifesta-se frequentemente de forma atípica, com lesões mais floridas, sendo também frequente a resistência à terapêutica clássica, resultando numa evolução prolongada.

Descreve-se o caso clinico de um homem de 25 anos, com antecedentes de imunodeficiência comum variável, que recorre à nossa consulta por ulcerações genitais extensas e exuberantes da região inguino-escrotal de etiologia herpética. Após terapêutica prolongada com valaciclovir, o doente mantinha-se sintomático, tendo-se optado pela associação de imiquimod $5 \%$ tópico, com resolução do quadro clínico e excelente tolerância.

O imiquimod, funcionando como um imunomodulador local, estimula a resposta imunológica antiviral. Configura-se assim como uma alternativa nos casos de infeções herpéticas de difícil controlo, especialmente em doentes imunodeprimidos.

PALAVRAS-CHAVE - Imiquimod; Ulcer; Herpes genitais; Herpes simples; Valaciclovir.

\section{RECALCITRANT HERPETIC GENITAL ULCERS TREATED WITH IMIQUIMOD IN ASSOCIATION WITH VALACYCLOVIR}

ABSTRACT - The herpes simplex virus is a common cause of genital ulcers. In the immunocompromised, it may have an atypical presentation, with exuberant lesions, frequently resulting in resistance to the mainstream therapeutic options, and a consequent prolonged course.

A 25-year-old male with a previous history of common variable immunodeficiency, presented with herpetic extensive genital ulcerations on the inguinoscrotal region. Despite a long period of valacyclovir therapy, the patient remained symptomatic. We decided to add topical $5 \%$ imiquimod as an adjunctive therapy, and observed a completed resolution of the ulcerations.

Imiquimod, working as a local immunomodulator, stimulates the anti-viral immunologic response. Therefore, it is an alternative in recalcitrant herpetic lesions, especially in the setting of immunosuppression.

KEY-WORDS - Imiquimod; Herpes genitalis; Herpes simplex; Ulcer; Valaciclovir.

Conflitos de interesse: Os autores declaram não possuir conflitos de interesse.

No conflicts of interest.

Suporte financeiro: O presente trabalho não foi suportado por nenhum subsídio ou bolsa.

No sponsorship or scholarship granted.

Direito à privacidade e consentimento escrito / Privacy policy and informed consent: Os autores declaram que pediram consentimento ao doente para usar as imagens no artigo. The authors declare that the patient gave written informed consent for the use of its photos in this article.

Recebido/Received - Agosto/August 2014; Aceite/Accepted - Setembro/September 2014 


\title{
GEIDST
}

\author{
Correspondência: \\ Dr. Diogo Matos \\ Serviço de Dermatovenereologia, \\ Hospital Garcia de Orta, \\ Avenida Torrado da Silva \\ 2801-951 Almada, Portugal \\ Email: diogomatos.pt@gmail.com
}

\section{INTRODUÇÃO}

O vírus herpes simplex (HSV) é a causa mais frequente de ulcerações genitais ${ }^{1-3}$. Em doentes imunocomprometidos, a sua apresentação é frequentemente atípica. São comuns lesões verrucosas hiperceratósicas, placas vegetantes erosionadas ou lesões hipertróficas por vezes com uma apresentação pseudo-tumoral, a qual pode levantar problemas de diagnóstico diferencial. Para além destas, é frequente uma evolução com ulcerações extensas, as quais tendem a ser crónicas, muitas vezes com superinfecção bacteriana. Este tipo de lesões são geralmente relatadas em doentes com $\mathrm{VIH}^{4}$, porém estão igualmente descritos casos em associação com neoplasias hematológicas, transplante de órgãos sólidos ${ }^{6}$ e imunodeficiências congénitas ${ }^{7}$.

A estas manifestações mais exuberantes, as quais por si só condicionam uma maior dificuldade no tratamento, junta-se uma crescente prevalência de estirpes de HSV resistentes ao aciclovir e valaciclovir. Esta resistência aparece com maior frequência (cerca de 5\%) em doentes imunocomprometidos, sobretudo $\mathrm{VIH}$, provavelmente em consequência de cursos terapêuticos mais prolongados e com doses mais altas com um carácter intermitente ${ }^{8,9}$.

\section{CASO CLÍNICO}

Descreve-se o caso clínico de um homem de 25 anos com história de imunodeficiência comum variável (ICV), para a qual fazia terapêutica periódica com imunoglobulina humana e.v., não tendo registadas intercorrências infecciosas nos últimos 3 anos. Recorre à nossa consulta por dermatose com 3 semanas de evolução, dolorosa, bilateral e simétrica afetando as pregas inguino-escrotais, escroto e região superior da face interna das coxas, composta por placas confluentes vegetantes ulceradas com exsudado sero-fibrinoso de cor amarelada (Fig. 1). Reportava, um primeiro episódio de ulcerações genitais, 9 meses antes, tendo sido admitida etiologia herpética e tratado com valaciclovir $1 \mathrm{~g}$ bid durante 10 dias. Referia, desde essa altura, mais 2 episódios com apresentação clínica semelhante, para os quais também foi tratado com valaciclovir $500 \mathrm{mg}$ bid durante 5 dias, verificando-se uma evolução para a cura, sem sintomatologia entre os mesmos. Perante o quadro clínico, compatível com herpes genital, e tendo em atenção os antecedentes pessoais, optou-se pelo tratamento com valaciclovir $1 \mathrm{~g}$ bid. O rastreio das restantes DST, nomeadamente $\mathrm{VIH}$, foi negativo. No final dos 10 dias de tratamento inicialmente programados, o doente foi novamente observado, não se verificando qualquer evolução positiva das lesões. Decidiu-se prolongar a terapêutica nas mesmas doses por mais 10 dias, tendo-se objectivado uma melhoria muito modesta. Nesta altura, considerando a possibilidade de uma superinfecção bacteriana, fez-se exame bacteriológico de uma das lesões, o qual evidenciou flora polimicrobiana. No seguimento deste resultado, instituiu-se cefradina $1 \mathrm{~g}$ bid durante 14 dias, mantendo-se o valaciclovir na mesma dose. Nesta mesma consulta, fez-se biopsia de uma das placas, a qual mostrou balonização do citoplasma dos queratinócitos, células gigantes multinucleadas, com espongiose da epiderme

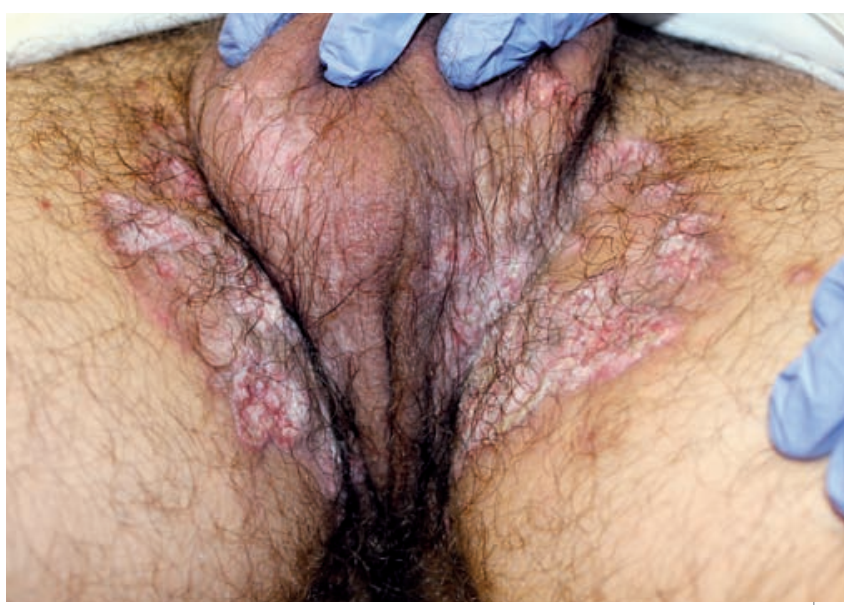

Fig 1 - Placas vegetantes ulceradas das regiões inguino-escrotais. 


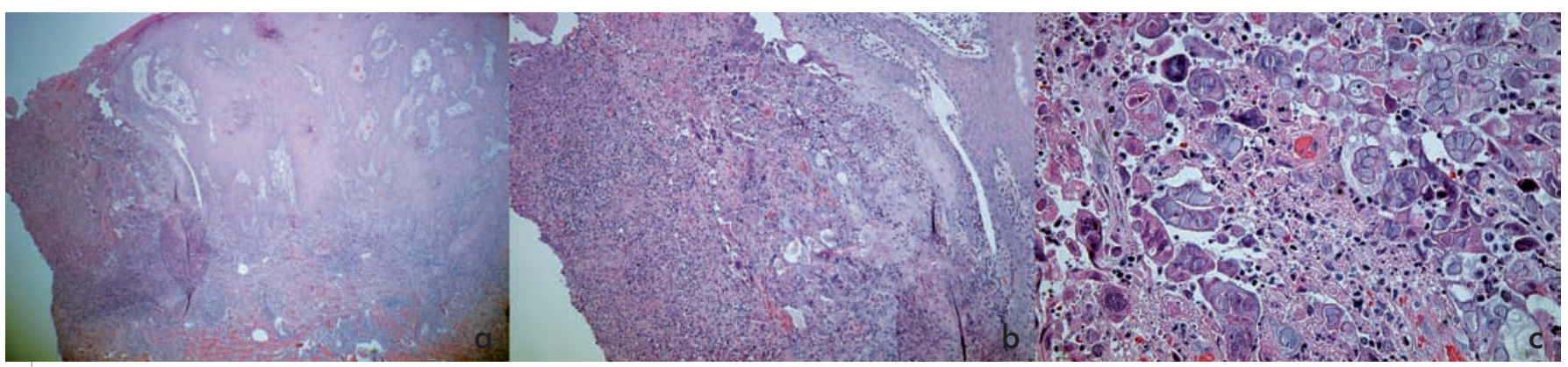

Fig 2 - Exame histopatológico onde são evidentes alterações decorrentes do efeito citopático viral. a) H\&E x40; b) H\&E x100; c) $H \& E \times 400$.

e vesículas intraepidérmicas, sendo evidente infiltrado inflamatório, predominantemente linfocítico, ao nível da derme (Fig. 2). Estes achados favoreciam a hipótese diagnóstica inicial. No final dos 14 dias de terapêutica antibiótica, e ao fim de 34 dias de valaciclovir $1 \mathrm{~g}$ bid, o doente evidenciava alguma melhoria, com diminuição das ulcerações, e consequentemente do exsudado, mas mantinha placas eritematosas vegetantes, as quais provocam desconforto marcado ao doente (Fig. 3). Por se ter verificado uma evolução positiva, manteve-se a terapêutica antiviral. $O$ doente foi reavaliado 2 semanas depois (48 dias após o início do tratamento), mantendo-se estacionário relativamente à avaliação prévia. Decidiu-se então pela prescrição de

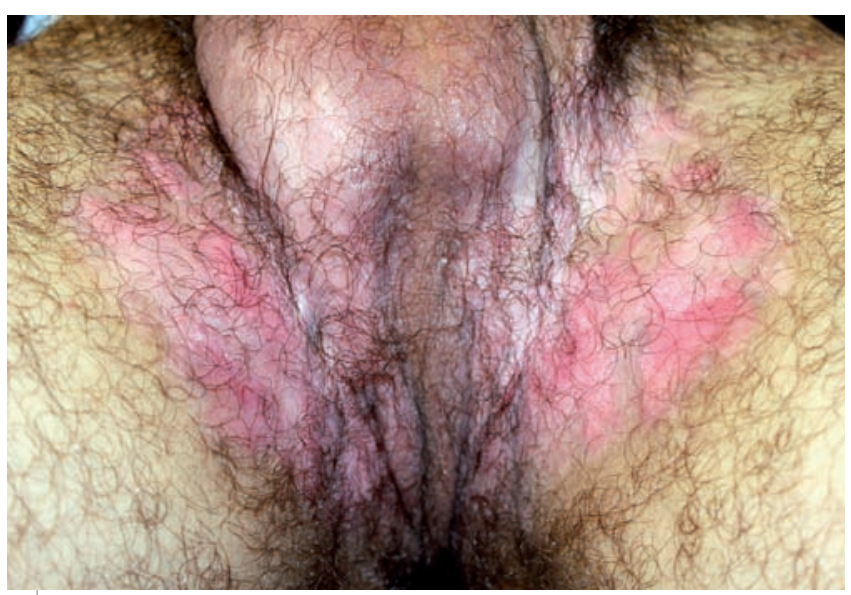

Fig 3 - Placas eritematosas com ulcerações discretas e ligeiramente exsudativas, 34 dias após início do tratamento.

imiquimod $5 \%$ tópico tiw durante 4 semanas, sem que se tenha interrompido o valaciclovir. Não se registaram efeitos secundários relevantes, nomeadamente ardor ou dor local observando-se uma melhoria franca com re-epitelização de todas as ulcerações, sendo apenas evidente hipopigmentação e discreto eritema em algumas áreas previamente afectadas (Fig. 4).

Manteve-se o tratamento com valaciclovir $1 \mathrm{~g} \mathrm{bid}$ durante mais 1 mês após a cura, altura em que se reduziu a dose para $1 \mathrm{~g}$ qd. Actualmente, 6 meses após a primeira consulta, o doente mantém-se assintomático, sem que se tenham registado novos episódios de ulcerações genitais.

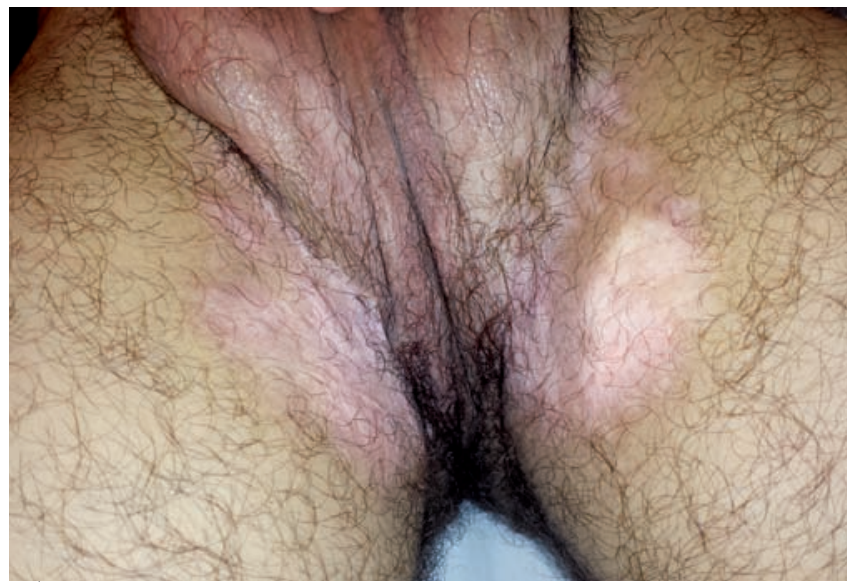

Fig 4 - Hipopimentação e Hiperpigmentação residuais com eritema muito discreto. Após tratamento com Imiquimod.

\section{DISCUSSÃO}

A ICV representa um grupo heterogéneo de imunodeficiências primárias que se caracterizam por hipogamaglobulinémia decorrente de uma disfunção dos linfócitos B, a qual confere uma susceptibilidade às infecções bacterianas. Contudo, em alguns doentes tem sido descrita uma associação com infeções virais, nomeadamente Citomegalovirus, Epstein-Barr e HSV, 
neste último caso, com episódios mais prolongados, recorrências mais frequentes e resistência à terapêutica. Esta predisposição aparece ligada à disfunção dos linfócitos $\mathrm{T}^{10}$, cursando com diminuição do ratio CD4/ CD8, observável num subgrupo de doentes com ICV ${ }^{1}$.

O caso clínico que se relata mostra esta dificuldade terapêutica, já que após cerca 7 semanas de valaciclovir em dose optimizada para imunocomprometidos, o doente, apesar de melhorado, mantinha-se sintomático e com lesões clinicamente apreciáveis. De acordo com o recomendado, deveria ter sido confirmada a etiologia das ulcerações genitais, por PCR ou cultura viral, e realizado um teste de resistência viral aos análogos dos nucleósidos (aciclovir e valaciclovir)². Nenhum destes métodos foi realizado, por indisponibilidade dos mesmos na nossa instituição. Contudo, os achados da biopsia, embora não permitam excluir outras etiologias, nomeadamente o CMV, apontam para uma etiologia herpética, sendo esta hipótese reforçada pelo carácter recidivante das ulcerações genitais previamente ao episódio que agora se descreve.

Para os casos de infecção herpética resistente à terapêutica clássica, por extrapolação do recomendado nos doentes com $\mathrm{VIH}$, as alternativas passam pelo foscarnet, talidomida, cidofovir tópico (não disponível em Portugal) ou imiquimod. Dados os potenciais efeitos secundários, os dois primeiros são reservados para casos mais graves e com comprovada resistência do HSV aos análogos dos nucleósidos. Surge assim o imiquimod como uma alternativa mais acessível, funcionando como terapêutica adjuvante aos análogos dos nucleósidos ${ }^{12,13}$.

Sendo um imunomodulador tópico, o imiquimod é, neste âmbito, mais frequentemente utilizado no tratamento das verrugas genitais provocadas pelo HPV. Contudo, o seu efeito antiviral é conhecido noutras patologias de etiologia viral, nomeadamente o molusco contagioso e o herpes genital. O imiquimod é um agonista do Toll-like receptor 7, estimulando, por esta via, a produção de diversas citoquinas, nomeadamente 0 TNF- $\alpha$, IL-12 e $\alpha$-IFN, os quais ajudam na construção de uma resposta Th 1 . Para além disto, o $\alpha$-IFN parece ter um efeito antiviral direto, diminuindo a propagação do HSV. Esta resposta imunológica local parece também ser mediada pela inibição da via do receptor $A 1$ da adenosina, aumentado a produção de cistatina $A$, uma inibidora da cisteína proteinase expressa abundantemente no epitélio cutâneo, onde se crê que desempenhe um papel na protecção contra infecções cutâneas, nomeadamente vírus, embora não se conheçam em pormenor os mecanismos deste efeito anti-viral ${ }^{14-17}$.
O nosso caso clínico ilustra a utilidade do imiquimod em casos de herpes genital recalcitrante, por se tratar de uma alternativa eficaz, prática, disponível e com efeitos secundários facilmente controláveis.

\section{REFERÊNCIAS}

1. Weiss $\mathrm{H}$. Epidemiology of herpes simplex virus type 2 infection in the developing world. Herpes. 2004; 11 (suppl 1):24A-35A.

2. Da Costa JB, Domingues D, Castro R, Exposto F. Úlceras genitais causadas por infecções sexualmente transmissíveis. Actualização do Diagnóstico e Terapêuticas,

3. e a sua Importância na Pandemia do VIH. Acta Med Port. 2006; 19(4):335-42.

4. Seara Alves S, Lisboa C, Xerinda S, Azevedo F. Herpes genital numa consulta de infecções sexualmente transmissíveis. Revista Soc Port Dermatol Venereol. 2007;65(1):57-63.

5. Safrin S, Ashley R, Houlihan C, Cusick PS, Mills J. Clinical and serologic features of herpes simplex virus infection in patients with AIDS. AIDS. 1991; 157:209-10.

6. Leming PD, Martin SE, Zwelling LA. Atypical herpes simplex (HSV) infection in a patient with Hodgkin's disease. Cancer. 1984; 54:3043-7.

7. Burke EM, Karp DL, Wu TC, Corio RL. Atypical oral presentation of herpes simplex virus infection in a patient after orthotopic liver transplantation. Eur Arch Otorhinolaryngol. 1994; 251(5):301-3.

8. Beasley KL, Cooley GE, Kao GF, Lowitt MH, Burnett JW, Aurelian L. Herpes simplex vegetans: atypical genital herpes infection in a patient with common variable immunodeficiency. J Am Acad Dermatol. 1997; 37(5 P+ 2):860-3.

9. Levin MJ, Bacon TH, Leary JJ. Resistance of herpes simplex virus infections to nucleoside analogues in HIV-infected patients. Clin Infect Dis. 2004; 39(Suppl 5):S248-57.

10. Andrei G, Snoeck R. Herpes simplex virus drug-resistance: new mutations and insights. Curr Opin Infect Dis. 2013; 26(6):551-60.

11. Notarangelo LD, Casanova JL, Conley ME, Chapel $\mathrm{H}$, Fischer A, Puck J, et al. Primary immunodeficiency diseases: an update from the international Union of Immunological Societies Primary Immunodeficiency Diseases Classification Committee Meeting in Budapest, 2005. J Allergy Clin Immunol. 2006; 117:883-96. 
12. Haveman LM, Scherrenburg J, Maarschalk-Ellerbroek LJ, Hoek PD, Schuurman R, de Jager W, et al. T-cell response to viral antigens in adults and children with common variable immunodeficiency and specific antibody deficiency. Clin Exp Immunol. 2010; 161(1):108-17.

13. Barde $C$, Piguet $V$, Pechère $M$, Masouye I, Saurat $\mathrm{JH}$, Wunderli $\mathrm{W}$, et al. Management of resistant mucocutaneous herpes simplex infections in AIDS patients: a clinical and virological challenge. HIV Med. 2011; 12(6):367-73.

14. Holmes A, McMenamin M, Mulcahy F, Bergin C. Thalidomide therapy for the treatment of hypertrophic herpes simplex virus-related genitalis in HIV-infected individuals. Clin Infect Dis. 2007; 44:96-9.

15. Lestre SI, João A, Carvalho C, Serrão W. Hypertrophic perianal herpes successfully treated with imiquimod. An Bras Dermatol. 2011; 86(6):1185-8.

16. Barbosa Ldo N, Souto R, Furtado AL, Gripp AC, Daxbacher E. Association of oral acyclovir and imiquimod for the treatment of hypertrophic genital herpes simplex in HIV positive patients: report of two cases. An Bras Dermatol. 2011; 86(5):1043-5.

17. Kan Y, Okabayashi T, Yokota S, Yamamoto S, Fujii $\mathrm{N}$, Yamashita T. Imiquimod suppresses propagation of herpes simplex virus 1 by upregulation of cystatin $A$ via the adenosine receptor $A 1$ pathway. J Virol. 2012; 86(19):10338-46.

18. McKendry A, Narayana S, Browne R. Atypical presentations of genital herpes simplex virus in HIV-1 and HIV-2 effectively treated by imiquimod. Int J STD AIDS. 2014 (in press). 